\title{
CAVE CARABIDAE (COLEOPTERA) OF MAMMOTH CAVE ${ }^{1}$
}

\author{
By Thomas C. Barr, Jr. \\ Department of Zoology, University of Kentucky, Lexington
}

In an earlier paper (Barr, 1962) I listed the troglobitic beetles known to inhabit Mammoth Cave, Mammoth Cave National Park, Kentucky. The species included several trechine carabids, one catopid (Ptomaphagus hirtus Tellk.), and one pselaphid (Batrisodes henroti Park). Further investigations in this huge cavern system and in surrounding caves have shown that there are actually 6 , instead of 4, species of trechines sympatric in Mammoth Cave. These include Neaphaenops tellkampfii Erichson, a large $(7 \mathrm{~mm})$ and very abundant species, and 5 species of the large genus Pseudanophthalmus Jeannel. The following key supersedes my earlier key (Barr, I962: p. 279) and is applicable only to Mammoth Cave National Park and caves in the immediate vicinity of Horse Cave, Cave City, and Park City.

Key to the Eyeless Cave Carabidae (Trechini) of Mammoth Cave National Park

I Size large $(6.5-7.5 \mathrm{~mm})$; one pair of supraorbital setae; elytron with only two discal punctures, the third, or posterior seta lacking; frontal grooves not extended onto sides of head; last segment of maxillary and labial palps much shorter than penultimate segment ....... Neaphaenops tellkampfi Erichson

Size smaller $(3.3-6.0 \mathrm{~mm})$; two pairs of supraorbital setae; elytron with 3 discal punctures, each bearing a short, stout seta or elytron with a single discal puncture near apex; frontal grooves extended onto sides of head; last segment of maxillary and labial palps subequal to penultimate segment (Pseudanophthalmus)

2

2( I ) Elytron with a single discal puncture near apex; mesosternum with a prominent median tubercle; length about $4 \mathrm{~mm}$; rare $P$. audax Horn

Elytron with 3 discal punctures; mesosternum simply declivous

'This investigation has been supported in part by grants from the $\mathrm{Na}$ tional Science Foundation (GB-2011, GB-5521).

Manuscript received by the editor November 30, 1966 
3(2) Size small, about $3.5 \mathrm{~mm}$; humeral margins entire; anterior discal puncture \pm at level of 4 th puncture in humeral margin; $0^{\lambda} O^{\lambda}$ with posterior margin of last sternite notched, aedeagus extremely elongate and slender; rare

$P$. inexpectatus Barr

Size larger, about 4.5-5.5 $\mathrm{mm}$; humeral margins serrulate; anterior discal puncture \pm at level of 2 nd puncture in humeral margin; $0^{\lambda} \sigma^{\lambda}$ with posterior margin of last sternite entire, aedeagus not extremely elongate and slender ………........ 4

4(3) Elytral disc densely and finely pubescent, longitudinal striae very regular and impunctate; sutural stria continued around apical margin of elytron and connected to 3 rd longitudinal stria; aedeagus broadly truncate at apex

P. pubescens Horn

Elytral disc glabrous or sparsely pubescent, striae evidently punctate; sutural stria continued only a short distance around apical margin of elytron, not clearly connected to apex of 3 rd longitudinal stria; apex of aedeagus attenuate

5(4) Elytral disc glabrous, longitudinal striae very shallow and coarsely and regularly punctate; base of pronotum turned obliquely forward behind the hind angles

P. menetriesii Motschulsky

Elytral disc sparsely pubescent, longitudinal striae deep and irregular, finely and distinctly punctate; hind angles projecting backward behind base of pronotum

P. striatus Motschulsky

In synonymizing $P$. striatus with $P$. menetriesii (Barr, 1962: p. 280) I was in error. The male genitalia of the two species are virtually identical, and cannot be used to separate them. The characters cited in the key are the most highly diagnostic, although $P$. striatus is a bit more slender and less depressed, the humeri are much less prominent, and there is usually a slight sinuosity of the elytral margin behind the humeral punctures.

The presence of several species of Pseudanophthalmus in Mammoth Cave raises the possibility of misinterpretation of the three trivial names proposed by Motschulsky ( 1862). Professor M. S. Ghilarov, President of the National Committee of Biologists of the Soviet Union, kindly arranged, at my request, to have specimens of the Mammoth Cave beetles compared with Motschulsky's types in the Zoological Museum of Moscow. Dr. K. V. Arnoldi, of the 
Moscow Branch of the All-Union Entomological Society, Academy of Sciences of the U. S. S. R., compared specimens of 5 Mammoth Cave trechines (all except $P$. audax) with the 3 examples of $A n$ ophthalmus striatus, $3 \mathrm{~A}$. menetriesii, and $2 A$. ventricosus in the Motschulsky collection. I)r. Arnoldi (in litt.) reports that the conventional interpretation of striatus and menetriesii, with ventricosus a synonym of menetriesii (Jeannel, 1928), is correct.

$P$. striatus is a riparian species in Mammoth Cave, apparently feeding on tubificid annelids in the silt banks along Lake Lethe and Echo River. In August, 1965, 'T. G. Marsh and I collected 30 Pseudanophthalmus at the margin of Lake Lethe, in dim illumination beside the electrically lighted tourist trail. Only one specimen of this series was $P$. menctriesii and the remainder were $P$. striatus. $O_{n}$ the other hand, menetriesii predominates in the upper levels of the cave, where most of the older collections seem to have been made.

In a study of distribution and variation in the menetriesii group Barr and Marsh (in preparation) have found that the range of menetriesii is a narrow belt not far removed from the I)ripping Spring escarpment. P. striatus, on the other hand, extends eastward across Barren County into the southwest corner of Metcalf County, where it is locally larger, more convex, and more difficult to separate morphologically from menetriesii. In Metcalf County striatus is sympatric with another, undescribed species of the menetriesii group. There is good evidence for character displacement where the range of striatus overlaps that of menetriesii or that of the undescribed species.

P. audax was known only from the type series (Barr, 1959), collected about 1880 in a cave 9 miles east of Mammoth Cave, until it was taken in White Cave, a half mile south-southwest of the $\mathrm{His}$ toric Entrance to Mammoth Cave, in August, 196r ( $\left.10^{x}\right)$, and August, 1965 ( 1 o ). The species occurred on wet, rotting wood at the back of White Cave, near an old bridge across a shallow pit. The pit is supposedly separated from Crevice Pit in Mammoth Cave only by a narrow crevice impenetrable to man. $P$. menetriesii, $P$. pubescens, $P$. inexpectutus, $P$. striatus, and $N$. tellkampfii have all been found at this place in the cave, either on the White Cave side of the crevice, the Mammoth Cave side, or both. Although I suggested that audax was probably "a rather curious offshoot from the menetriesii-robustus branch of the genus" (Barr, 1959: p. 3), further study of the genus has shown that this species should form the type of an audax group (as suggested by Jeannel, 1949), to include $P$. 
horni Garman (caves near Lexington, Kentucky), $P$. e emersoni Krekeler (caves near Bedford, Indiana), P. packardi Barr (Carter Co., Kentucky), and various undescribed species from central Kentucky. The group is characterized by medium size (about $4 \mathrm{~mm}$ in total length), prominent humeri with finely serrate margins, and a mesosternal spine or tubercle (or at least a vertical shelf when the mesosternum is viewed in profile). 

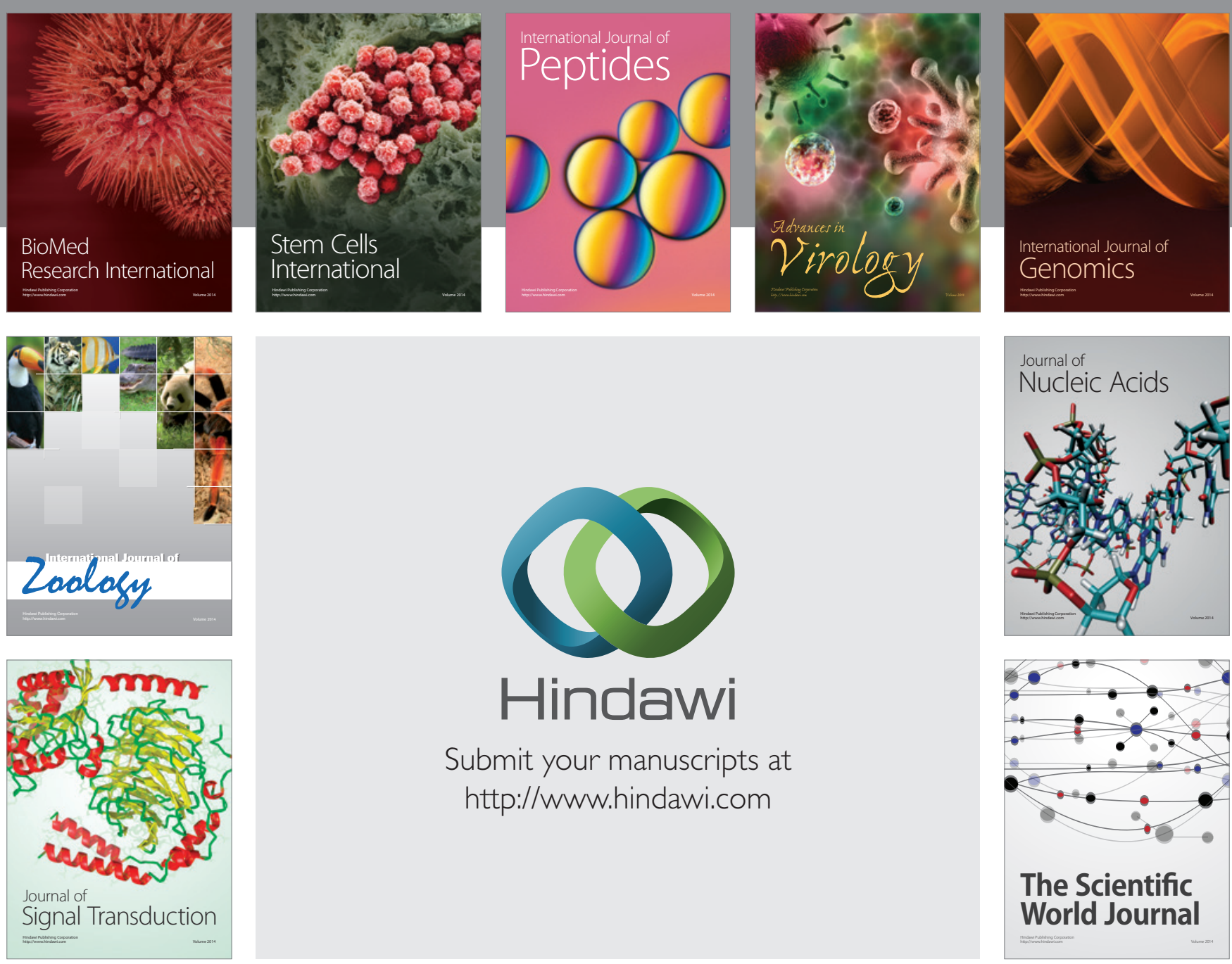

Submit your manuscripts at

http://www.hindawi.com
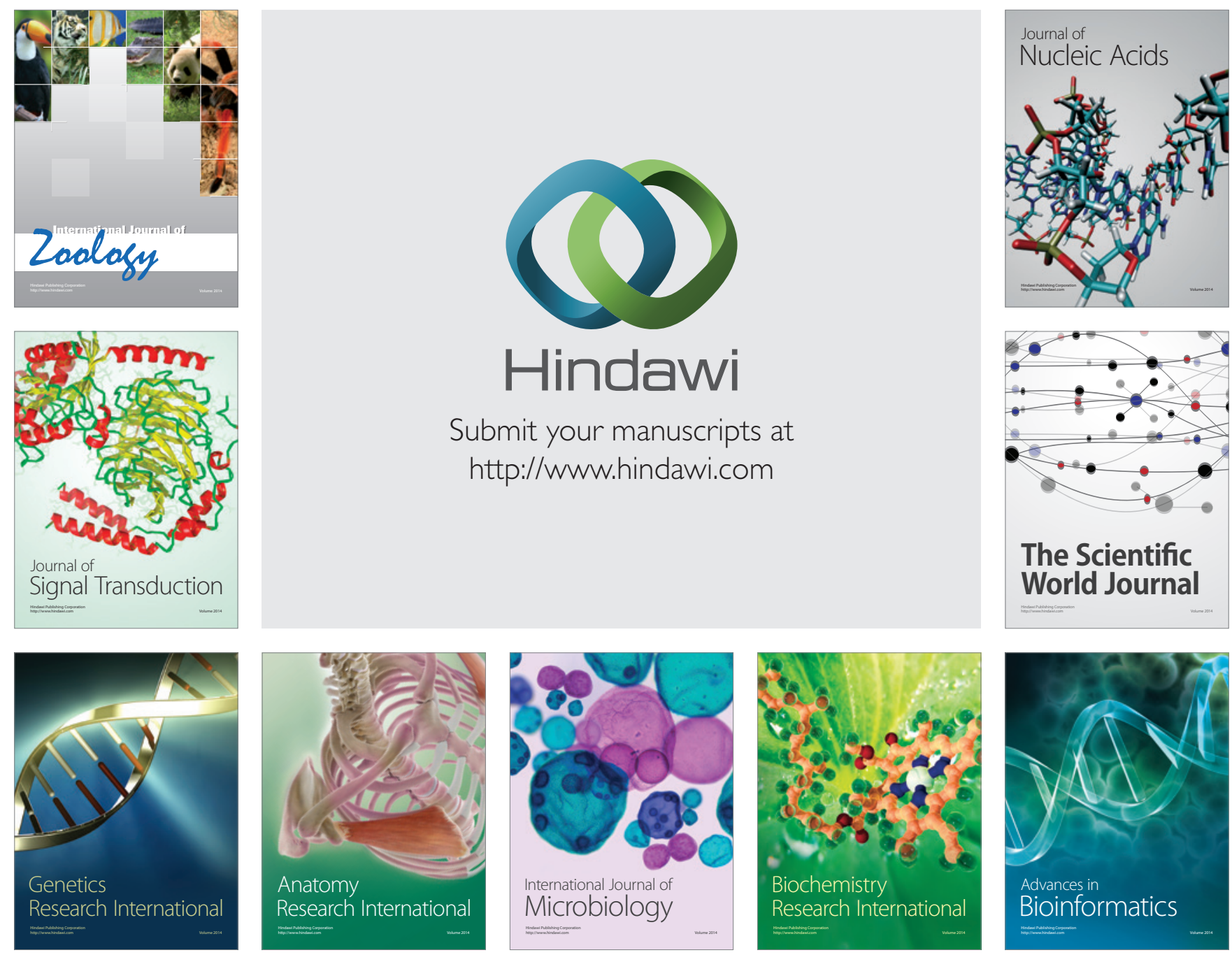

The Scientific World Journal
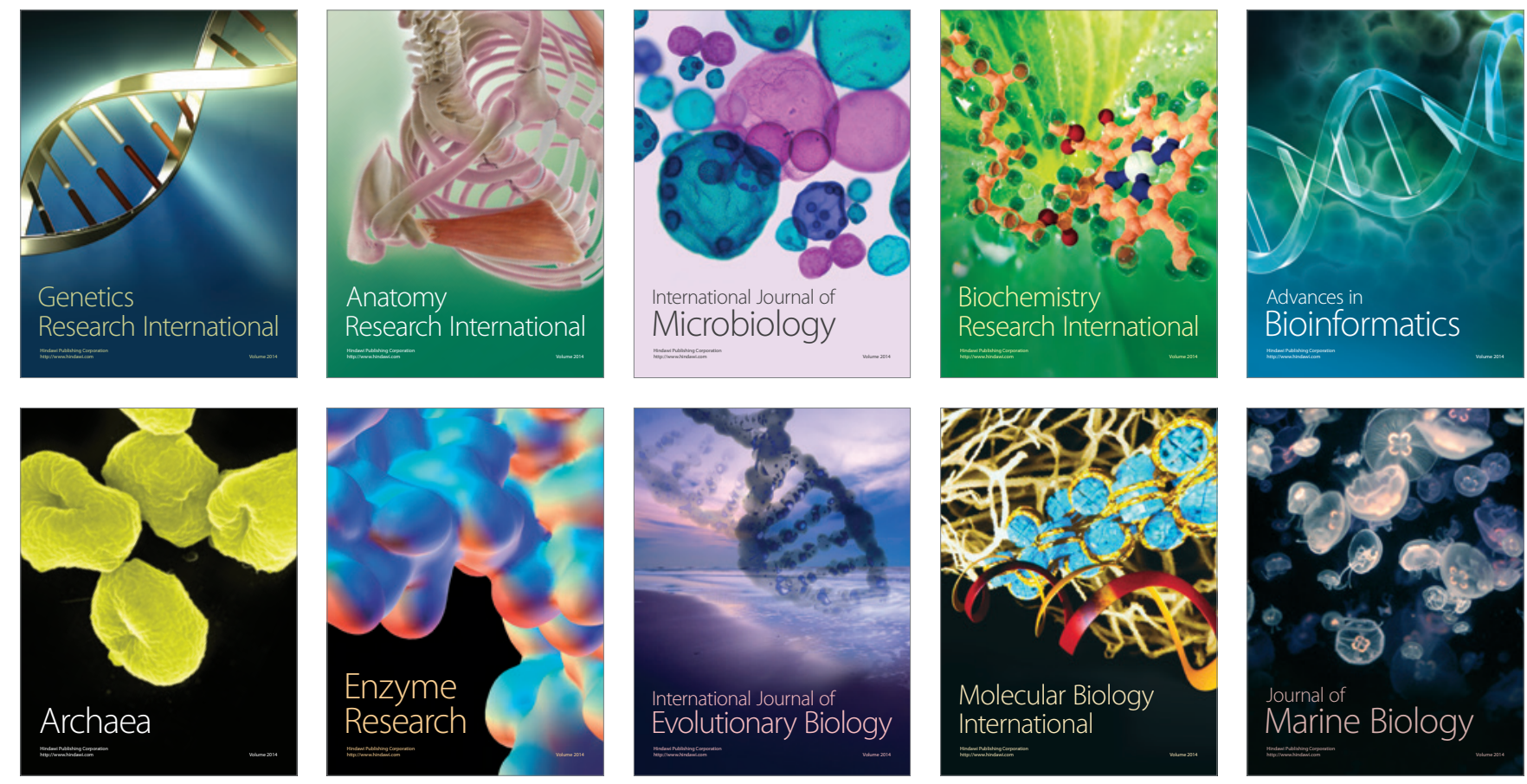